\title{
Polymer light-emitting devices using poly(ethylene oxide) as an electron injecting layer
}

\author{
M. V. Madhava Rao*, Tsung-Syun Huang, Yan-Kuin Su, Ming-Lung Tu, Chun-Yuan Huang and Shang-Shung \\ $\mathrm{Wu}$
}

The performance of polymer light emitting devices (PLEDs) based on polyvinyl carbazole (PVK) is improved by introducing a nanoscale interfacial thin layer, made of poly(ethylene oxide) (PEO), between the calcium cathode and the PVK emissive layer. It is believed that the PEO layer plays a key role in enhancing the device performance. In comparison to the device with $\mathrm{Ca} / \mathrm{Al}$ as the cathode, the performance of the PLED with $\mathrm{PEO} / \mathrm{Ca} / \mathrm{Al}$ cathode, including the driving voltage, luminance efficiency is significantly improved. These improvements are attributed to the introduction of a thin layer of PEO that can lower the interfacial barrier and facilitate electron injection.

Keywords: Polymer light emitting devices; Electron injection layer; Electroluminescence

Citation: M. V. Madhava Rao, Tsung-Syun Huang, Yan-Kuin Su, Ming-Lung Tu, Chun-Yuan Huang and Shang-Shung $\mathrm{Wu}$, "Polymer light-emitting devices using poly(ethylene oxide) as an electron injecting layer", Nano-Micro Lett. 2, 49-52 (2010). doi: 10.5101/nml.v2i1.p49-52

Polymer light-emitting diodes (PLEDs) have attracted much interest worldwide since their discovery by Friend and co-workers in 1990 [1]. Engineering of the polymer-electrode interfacial properties is crucial to achieve balanced hole and electron injection for high efficiency operations. Low work function metals, such as calcium or barium are widely used as a cathode to facilitate electron injection [2-8]. These metals are very sensitive to moisture and oxygen and form detrimental quenching sites at areas near the interface between the electroluminescent (EL) layer and the cathode. In addition, metal ions formed at the metal/organic interface tend to migrate into the EL layer, thus, affecting the long term stability of devices [9]. To circumvent these problems, it is desirable to use high work-function metals (such as $\mathrm{Al}, \mathrm{Ag}$, or $\mathrm{Au}$ ) as the cathode because of their better environmental stability and the simplicity of their device fabrication. To improve electron injection from high-work-function metals into the emitting layer, numerous approaches have been attempted [10,11]. For example, by inserting a thin layer of lithium fluoride, or cesium fluoride, between $\mathrm{Al}$ and the light emitting layer, the electron-injection ability could be significantly improved [10-12]. It was shown by the Cao et al. that the insertion of organic surfactant molecules between $\mathrm{Al}$ and the EL polymer could improve device performance up to the level obtained by low-work function metal cathode [11]. Li et al. reported that effective electron injection can be achieved by the insertion of an ultrathin aluminum oxide layer between the $\mathrm{Al}$ and the emitting layer [13]. Lee et al. reported that polystyrene sodium sulfonate inserted between MEH-PPV and Al significantly improves electron injection [14]. Guo et al. reported that high performance polymer and small molecule OLEDs with an organic oxide, poly(ethylene glycol) dimethyl ether (PEGDE). Because PEGDE can be evaporated at low temperature compared to other inorganic insulators and improves the device performance as much as the inorganic electron injection layers, it could be a good candidate for an organic electron injection layer [15-17]. In this study, the performance of PVK based PLEDs is improved by using $\mathrm{PEO} / \mathrm{Ca} / \mathrm{Al}$ cathode. When a thin PEO $(5 \mathrm{~nm})$ buffer layer is introduced between the PVK emissive layer and the $\mathrm{Ca}$ cathode, the driving voltage of the device is reduced and the light efficiency is enhanced.

\section{Experimental details}

The ITO coated glass with a sheet resistance of $25 \mathrm{ohm} / \mathrm{cm}$ was used for the anode for PLED fabrication. For the preparation of PLEDs, the ITO glass was cleaned sequentially in ultrasonic bath of isopropanol, acetone, and de-ionized water. Finally, the ITO glass was sonicated in deionization water and then blown dry with $\mathrm{N}_{2}$ gas. The poly(styrenesulfonate) 
(PSS)-doped poly(3,4-ethylenedioxythiophene) (PEDOT) was used as the hole transport layer (HTL). A $40 \mathrm{~nm}$ thick PEDOT:PSS was spin coated onto precleaned and UV-O ${ }^{3}$ treated ITO substrates. The PEDOT:PSS layer was first baked at $150^{\circ} \mathrm{C}$ for $30 \mathrm{~min}$ to remove residual water and then moved into a glovebox under $\mathrm{N}_{2}$ filled environment. The electroluminescent (EL) polymer films (PVK) was spin coated from solution to form different thickness on top of the PEDOT:PSS layer. The sample was baked at $60^{\circ} \mathrm{C}$ for $30 \mathrm{~min}$ to remove the residual solvent. Finally a $\operatorname{PEO}(5 \mathrm{~nm}) / \mathrm{Ca}(60$ $\mathrm{nm}) / \mathrm{Al}(200 \mathrm{~nm})$ thick metal cathode film was thermally deposited through a shadow mask to form top electrode in a vacuum of $1 \times 10^{-6}$ Torr. EL spectra and CIE coordination of the devices were measured by PR650 spectra scan spectrometer and the current-voltage-brightness characteristics were simultaneously measured by a Keithley 2400 programmable voltage-current source. All the measurements were carried out at room temperature under ambient conditions. Figure 1 shows the device structure used in this study. The active emissive area of the device is $6 \mathrm{~mm}^{2}$.

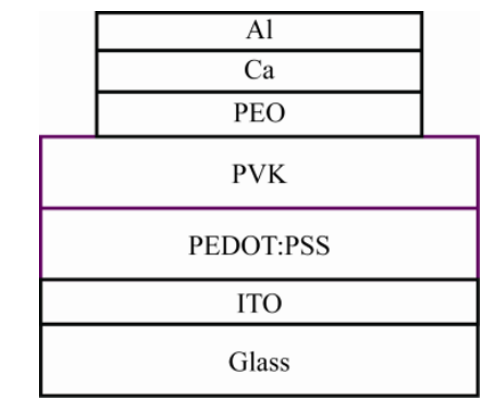

FIG. 1 Schematic diagram of our PLED structure.

\section{Results and Discussion}

Figure 2 shows the current-voltage (I-V) characteristics of the different concentration of PVK. It was found that the $1 \mathrm{wt} \%$ device showed better performance compared to those of devices $2 \mathrm{wt} \%$ and $3 \mathrm{wt} \%$. The turn-on voltage (7V) is the best for the device with $1 \mathrm{wt} \%$. However for the other two $(2 \mathrm{wt} \%$ and 3 $\mathrm{wt} \%$ ) PLEDs did not emit light. LUMO of $\mathrm{Ca}$ is $-2.9 \mathrm{eV}$ and LUMO of PVK is $-2.3 \mathrm{eV}$, so it has a very high barrier for electron hopping. It will lead to the unbalance of electrons and holes. The electrons can not normally be injected from cathode

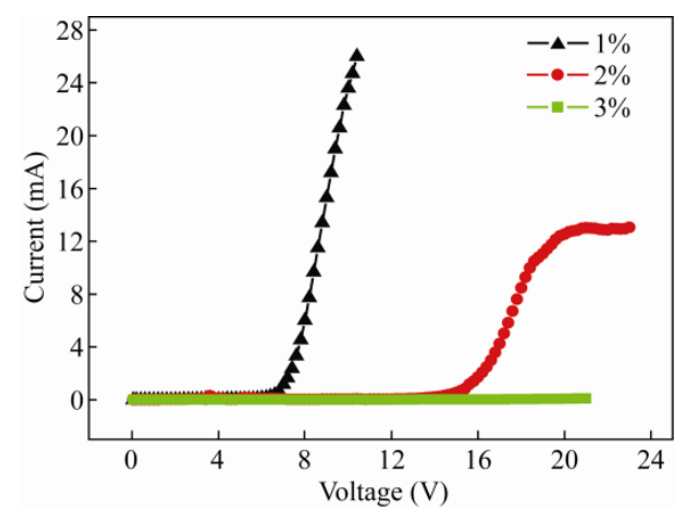

FIG. 2. Current-Voltage characteristics of the device with configuration of ITO/PEDOT:PSS/PVK/Ca/Al. to emitting layer, due to the high energy barrier between them. Therefore we used the electron injection layer poly ethylene oxide (PEO) [18-20]. We have inserted the electron injection layer between cathode and the emitting layer by thermal evaporation.

Figure 3(a) shows the I-V curves for the devices made using $\mathrm{PEO} / \mathrm{Ca} / \mathrm{Al}$ as the cathode at various spin casting speeds of the PVK layer. The turn-on voltage decreased with increasing spin speed. The best spin speed and turn-on voltage were at $4000 \mathrm{rpm}$ and $4.9 \mathrm{~V}$. The turn-on voltage was reduced as the PVK film thickness decreased. The turn-on voltage at $2000 \mathrm{rpm}$ and $3000 \mathrm{rpm}$ were $6.5 \mathrm{~V}$ and $5.5 \mathrm{~V}$, respectively.
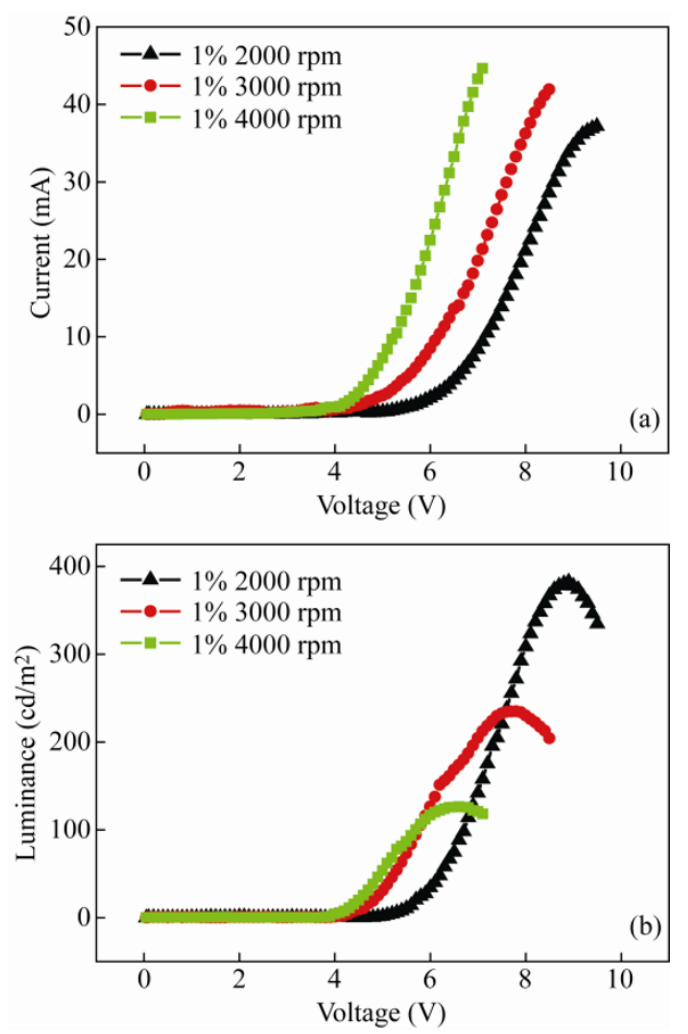

FIG. 3. (a) Current-Voltage; (b) Brightness-Voltage characteristics of PLEDs with different spin-speeds, the device configuration is ITO/PEDOT: $\mathrm{PSS} / \mathrm{PVK} / \mathrm{PEO} / \mathrm{Ca} / \mathrm{Al}$.

The brightness versus (L-V) voltage characteristics were shown in Fig. 3(b). The maximal luminance at $2000 \mathrm{rpm}$ spin speed was $382 \mathrm{~cd} / \mathrm{m}^{2}$. However, the maximal luminance at $3000 \mathrm{rpm}$ and $4000 \mathrm{rpm}$ were $234 \mathrm{~cd} / \mathrm{m}^{2}$ and $126 \mathrm{~cd} / \mathrm{m}^{2}$, respectively.

Figure 4 shows the typical relationship among luminance efficiency, and current of $\mathrm{PVK}(1 \mathrm{wt} \%)$ deposited at different spin speeds of 2000, 3000 and $4000 \mathrm{rpm}$ for the polymer light emitting devices which exhibit maximum luminance efficiency of $0.105 \mathrm{~cd} / \mathrm{A}, 0.094 \mathrm{~cd} / \mathrm{A}$, and $0.00445 \mathrm{~cd} / \mathrm{A}$ respectively. The device with a concentration of $1 \mathrm{wt} \% \mathrm{PVK}$ and with a spin speed of $2000 \mathrm{rpm}$ showed better properties. The normalized electroluminescence as a function of the emission wavelength of PLEDs with different spin speeds of PVK is shown in Fig. 5(b). Electroluminescence intensity produced by the devices is increasing with the decreasing spin speed of the PVK layer. There were three peaks at 440, 480 and $600 \mathrm{~nm}$ in Fig. 5(b). The PL spectrum of PVK showed only one peak at $410 \mathrm{~nm}$ (see Fig. 5(a)), but its EL spectrum showed three peaks. The first 
peak was generated from intra-chain transition, and the other peak was generated from inter-chain transition.

The detailed device characteristics of the devices with different cathodes are summarized in Table I. For the device with $\mathrm{Al}$ cathode, a large turn-on voltage is needed to achieve a luminance of $1 \mathrm{~cd} / \mathrm{m}^{2}$. However, when a Ca/Al layer cathode is used, the turn-on voltages of the device are reduced in comparison with $\mathrm{Al}$ device. Most importantly, as the device with $\mathrm{PEO} / \mathrm{Ca} / \mathrm{Al}$ cathode is used, the turn-on voltage is greatly reduced in comparison with $\mathrm{Al}$ and $\mathrm{Ca} / \mathrm{Al}$ devices.

The insertion of PEO layer could increase performance as compared to $\mathrm{Ca} / \mathrm{Al}$ and $\mathrm{PEO} / \mathrm{Ca} / \mathrm{Al}$ devices. Because the electron could hardly get injected from $\mathrm{Ca}$ to $\mathrm{PVK}$, the addition of PEO between emitting layer and cathode layer could improve this condition. However, the insertion of PEO could let electrons inject to emitting layer. The electrons in emitting layer were increased. The recombination of electron-hole pair in PVK leads to emission of light. The device performance was enhanced by placing a monolayer of PEO at the contact interface between EL layer and the cathode, into the EL polymer layer [19]. In spite of the bulk resistance and the barrier height of PEO being much higher than that of the EL layer, the higher luminescence intensity and efficiency of devices suggest the injection of minority carriers (electrons) to be enhanced in their device configuration.

\section{Conclusions}

In summary, we have investigated the polymer light emitting diodes by using a PEO nanoscale interfacial layer to modify the cathode interface. It is found that the PLED could emit light and improve efficiency. Because electron injection function was increased by inserting PEO, the electron and hole were balanced in emitting layer. The electron-hole pair was

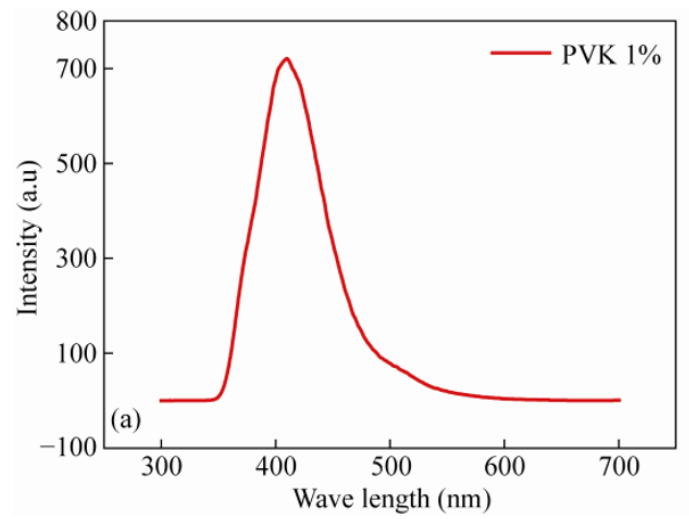

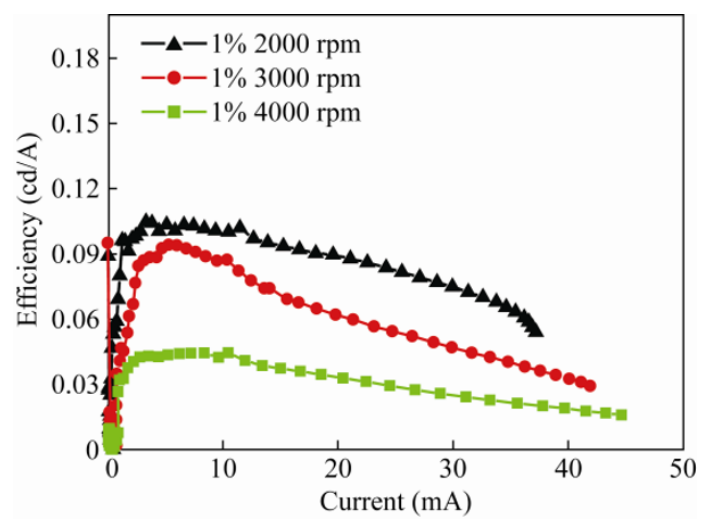

FIG.4. EL efficiency-current characteristics of the devices with different spin speeds.

recombined in PVK layer and light was emitted. The turn-on voltage is about $6.5 \mathrm{~V}$, the maximal luminance and luminance efficiency are $382 \mathrm{~cd} / \mathrm{m}^{2}$, and $0.105 \mathrm{~cd} / \mathrm{A}$.

The authors would like to thank the Office of R\&D, National

Cheng Kung University, Taiwan.

Received 3 March 2010; accepted 29 March 2010; published online 31 March 2010.

\section{References}

1. J. H. Burroughs, D. D. C. Bradley, A. R. Brown, R. N. Marks, K. Mackay, R. H. Friend, O. L. Burns and A. B. Holmes, Nature (London) 347, 539 (1990). doi:10.1038/ $\underline{347539 \mathrm{a} 0}$

2. D. Braun and A. J. Heeger, Appl. Phys. Lett. 58, 1982 (1991). doi:10.1063/1.105039

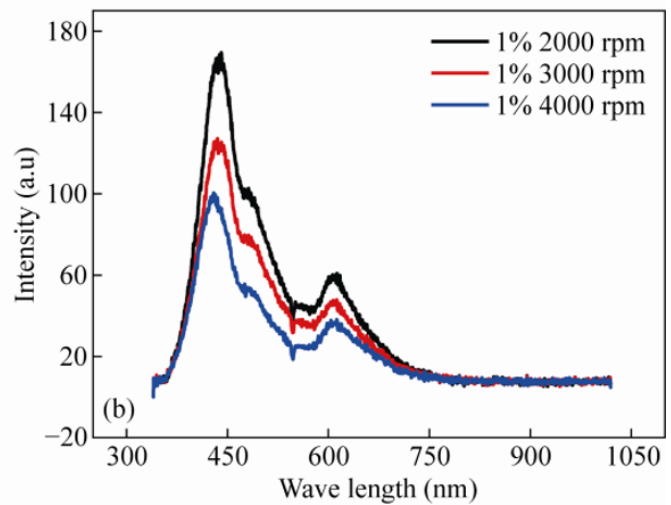

FIG. 5. (a) PL spectra of PVK; (b) Normalized EL emission spectra of the devices with different spin speeds.

TABLE 1. Performance of PVK-based PLEDs made with different cathodes.

\begin{tabular}{ccc}
\hline Cathode Structure & turn-on voltage & maximum luminance \\
& $(\mathrm{V})$ & Large* $\left./ \mathrm{m}^{2}\right)$ \\
$\mathrm{Al}$ & 7 & no light \\
$\mathrm{Ca} / \mathrm{Al}$ & & no light \\
$\mathrm{PEO} / \mathrm{Ca} / \mathrm{Al}$ & 6.5 & 382 \\
\hline
\end{tabular}

*Large means the voltage is beyond the range of measured equipment 
3. J. Kalinowski, Dekker, New York, USA, 2005.

4. H. S. Yang and P. H. Holloway, J. Phys. Chem. B 107, 9705 (2003). doi:10.1021/jp034749i

5. F. S. Li, Z. J. Chen, W. Wei and Q. H. Gong, Org. Electron. 6, 237 (2005). doi:10.1016/j.orgel.2005.08.002

6. C. Tengstedt, A. Crispin, C. H. Hsu, C. Zhang, D. Parker, W. R. Salaneck and M. Fahlman, Org. Elect. 6, 21 (2005). doi:10.1016/j.orgel.2005.02.001

7. S. Coe. Sulliyan, W. K. Woo, J. S. Steckel, M. Bawendi and V. Bulovic, Org. Elect. 4, 123 (2003).

8. M. Cocchi, J. Kalinowski, D. Virgili and J. A. G. Williams, Appl. Phys. Lett. 92, 113302 (2008). doi:10.1063/1.289 $\underline{8159}$

9. I. D. Parker, Y. Cao and C. Y. Yang, J. Appl. Phys. 85, 2441 (1999). doi:10.1063/1.369564

10. L. S. Hung, C. W. Tang and M. G. Mason, Appl. Phys. Lett. 70, 152 (1997). doi:10.1063/1.118344

11. Y. Cao, G. Yuand and A. J. Heeger, Adv. Mater. 10, 917 (1998). doi:10.1002/(SICI)1521-4095(199808)10:12<917: AID-ADMA917>3.0.CO;2-K

12. P. Piromerium, H. Oh, Y. Shen, G. G. Malliaras, J. C. Scott and P.J. Brock, Appl. Phys. Lett. 77, 2403 (2000). doi:10.1063/1.1317547
13. F. Li, H. Tang, J. Anderegg and J. Shinar, Appl. Phys. Lett. 70, 1233 (1997). doi:10.1063/1.118539

14. H. M. Lee, K. H. Choi, D. H. Hwang, L. M. Do, T. Zyung, J. W. Lee and J. K. Park, Appl. Phys. Lett. 72, 2382 (1998). doi: $10.1063 / 1.121363$

15. T. F. Guo, F. S. Yang, Z. J. Tsai, T. C. Wen, S. N. Hsieh, Y. S. Fu and C. T. Chung, Appl. Phys. Lett. 88, 113501 (2006). doi:10.1063/1.2183808

16. T. F. Guo, F. S. Yang, Z. J. Tsai, G. W. Feng, T. C. Wen, S. N. Hsieh, C. T. Chung and C. I. Wu, Appl. Phys. Lett. 89, 051103 (2006). doi:10.1063/1.2234317

17. T. F. Guo, F. S. Yang, Z. J. Tsai, T. C. Wen, C. I. Wu and C. T. Chung, Appl. Phys. Lett. 89, 053507 (2006). doi:10.1063/1.2266571

18. J. W. Stouwdam and R. A. J. Janssen, J. Mater. Chem. 18, 1889 (2008). doi:10.1039/b800028j

19. T. F. Guo, F. S. Yang, Z. J. Tsai, T. C. Wen, S. N. Hsieh and Y. W. Fu, Appl. Phys. Lett. 87, 013504 (2005). doi:10.1063/1.1984101

20. R. K. Ligman, L. Mangolini, U. R. Kortshagen and S. A. Campbell, Appl. Phys. Lett. 90, 061116 (2007). doi:10. $\underline{1063 / 1.2471662}$ 